\title{
Work-Life Balance and Role Conflict among Academic Staff in the Middle East: A Review of Literature
}

\author{
Dr. Ahmed M. Asfahani ${ }^{1}$ \\ ${ }^{1}$ University of Business and Technology, Jeddah, Saudi Arabia \\ Correspondence: Dr. Ahmed M. Asfahani, University of Business and Technology, Jeddah, Saudi Arabia.
}

Received: March 18, 2021

Accepted: April 26, 2021

Online Published: April 27, 2021

doi:10.5430/ijhe.v10n5p82

URL: https://doi.org/10.5430/ijhe.v10n5p82

\begin{abstract}
Family and work are fundamental aspects of life, and an individual must find a balance between both. Prioritizing one over the other can cause distress in one's life. Every individual plays an important role in their work and non-work/personal life with the aim of fulfilling their needs, but it's not always easy to find a balance, which may cause a conflict. The reasons behind this conflict vary according to different professional constraints such as working hours, work environment, nature of job, and interpersonal relations. Non-work and personal factors such as: marital status, number of children, home environment, age, gender, and location may also contribute. This paper aims to study the importance of work-life balance in reducing role conflict among academic staff in the Middle Eastern region.
\end{abstract}

Keywords: work-life balance, conflict, Middle East, conversation of resources theory, role theory

\section{Introduction}

The previous two decades have seen increased interest in work-life balance, which has, lately, become an important symbol of an individual's wellbeing and happiness. An imbalance in the work-family relationship can cause health problems and decrease performance outcomes at work. Work-Life Balance (WLB) refers to the lack of equilibrium between one's career and other roles of life, such as an uneven amount of time divided between work and family. There are different definitions for WLB; Karakas and Lee (2004) defined it as having a good time with family members, being able to spend enough time on one's emotional wellbeing and health, a good level of communication and support from peers at work, and job satisfaction (being satisfied with the workload). Having a good communication level with colleagues is also important in maintaining this balance (Eisenkopf, 2018).

A work role is a specific position assigned to an individual that comes with certain responsibilities. Similarly, one plays a role in his/her personal life as well. Role conflict refers to incompatibility or inconsistency in meeting the demands of different roles (Bowling, et al., 2017). According to Javed et. al. (2014) the ambiguity in prioritizing two conflicting tasks is called role conflict. A study by Asif Iqbal et al. (2020) shows that both work and family are important aspects of an elementary school teacher's life. If one creates a competition between them, he would be asking for a conflict. Role theory implies that failure to perform different roles of life simultaneously can generate a conflict. Three problems that are fundamental to conflict are: time, strain and behavior.

1. Time: Inability to perform more than one role at a time can generate conflict. To minimize this conflict one has to find a balance between work and non-work roles.

2. Strain: Stress generated from the performance of a role that makes it hard to meet the requirements of another role.

3. Behavior: Shifting from one role behavior to another may also cause conflict. All roles have their own requirements and intermixing the requirements of different roles can be harmful for work-life balance, thus initiating a conflict.

Evidence from literature suggests that role conflict between work and family affects a person's health and wellbeing, and it has now become a common problem among professionals. There has been considerable research on this topic globally but most of it has been conducted in developed countries. According to Hofstede (1984), this conflict varies across cultures - owing to differences in norms, values and beliefs.

\section{Methodology}

The information for this study was collected from past studies and reviews on WLB and Role Conflict among 
academicians from middle-east. The data used is secondary in nature which was collected from published sources i.e. Journals, websites and books. For this study the articles were searched using different keywords, according to the purpose of this study, on different databases (Science Direct, Google Scholar, Elsevier, Scopus, Web of Science and Research Gate). Keywords used for the search included work-life balance, role conflict, conflict management, work-family balance, work and family role conflict, work-family conflict.

\section{Work Life Balance and Role Conflict among Middle Eastern Academic Staff}

The education system of the Middle East mainly focuses on improving education standards and instilling a higher level of professionalism. Many people are employed as academic staff because of the importance of education in the Middle East. Given the importance of the education system, countries need to support their academic staff; for this purpose, they need to discover new and innovative ways to retain their academic staff. The educational institutions are providing flexible programs according to the needs of students. In order to maintain high education standards and meet the needs of students, the academic staff may feel stressed at their jobs because of the workload and trying to attain work-life balance. Furthermore, with increasing pressure to maintain higher education levels, compared to international education levels, the policies of the education system have been changing. These changes can really challenge the students' ability to learn, thus increasing the workload of the academic staff, because they have to teach the students new skills to meet the demands of the industry. Furthermore, there is very little research on the causes and effects of work-life balance in reducing role conflict on academic staff in the universities in the Middle East. Therefore, this study is an attempt to analyze the role of work-life balance in reducing role conflict among the academic staff working in universities in the Middle East.

With an increase in workload, the pressure to find a balance between work and non-work activities has also increased in many countries. According to a study in Dubai — an important trade center of the Middle East region—over 42\% of the working population are facing work pressure at their jobs and over 50\% wish to leave their current jobs but cannot do so because of personal financial problems and career growth. The author states that "personal financial problems, children's education, loans for car etc., causes stress at jobs" (Maceda, 2016). The employees facing these problems feel extra pressure while making a decision regarding their financial problems, since these are connected to their job-related decisions. The academic staff from universities in the UAE are facing problems at work as many employees of these universities are subjected to permanent work-related stress, thus affecting their personal and professional lives (Chapman, Austin, Farah, Wilson, \& Ridge, 2013). Lecturers and other staff working at the universities generally face insecurities with regard to being easily replaceable, due to the nature of their contract or short-term employment opportunities (Bodla, Hussain, \& Chen, 2014).

WLB has become an important part of the realities of daily life. Employees are forced to do more work; this leads to stress that has become a huge challenge for organizations and their employees. Balancing work and non-work roles is a necessity of life nowadays and the inability to do so results in role conflict. Role conflict arises when an individual cannot balance between two (or more) pressures occurring simultaneously. Conservation Theory of Resources (CTR) provides one additional explanation of the phenomenon. According to the CTR, stress is triggered when an individual is either afraid of a potential loss of resources, actually going through a resource loss or fails to acquire the expected amount of resources. This theory also suggests that several work and non-work roles played by an individual require balancing and an increase in the competition over resources may lead to job dissatisfaction. To avoid this situation, one must take work-life balance problems seriously (Agha \& Khan, 2019).

According to Kakul and Khan (2019), female teachers are more affected by their personal life, compared to male teachers in Oman. However, the nature of the job and work environment plays an important role in balancing work and life.

The traditional roles of men and women are still dominant in the Middle East. Previously, men were the bread winners, while women used to fulfill the responsibilities of housekeeping, such as cleaning, doing the laundry, cooking and other household chores. However, trends are now shifting, social and economic changes are occurring gradually, similar to Western societies and as a result, traditional families are morphing into dual-career families [ (Karimi, 2008); (Tavassoli \& Sune, 2018)]. Dual-career families lead to work and family being inter-connected. This shift may increase the responsibilities at home and at work, making the act of maintaining a balance between these intertwined domains even more difficult, which can result in an increase in psychological distress (Nishaat, 2017). This psychological distress perturbs the employees, thus preventing them from doing their best at work (Javed, Khan, Yasir, Aamir, \& Ahmed, 2014).

A considerable increase in dual-career families, single parents, and a decrease in the number of sole breadwinners in families has increased the overall responsibilities relating to work, family, household, etc. This increase in 
responsibilities has also challenged the work-life balance and increased role conflict among female teachers in the UAE. The burden increases with a change in the marital status of female teachers, due to the increased responsibilities of taking care of households and children, along with managing their professional lives (Haider \& Agha, 2019).

A survey by S Bayraktaroglu et al. (2019) found that academics in business schools in Turkey have a higher level of family-work and work-family conflict compared to business schools in the UK, resulting in lower life-satisfaction. They also suggested that employees belonging to different cultural settings can cause work-family conflict.

The teaching profession has many duties and managing these duties can be very challenging, leading to stress and burnout. Heavy workloads with time constraints cause pressure, making it difficult to balance work and non-work responsibilities and this may cause a failure to maintain work-life balance. Finding a work-life balance means finding an equilibrium between work and personal activities. Policies at work enable employees to find the balance between daily work and non-work activities, thus initiating role conflict. Stress plays a major role during the process of finding this balance, and it is important to minimize its impact before it becomes unmanageable (Anaele).

The number of work hours in the UAE determines the level of stress and job satisfaction among academics. The survey suggested that $51 \%$ of academic staff work for 7 hours, while $32 \%$ spend 8 hours in the university. The number of academics spending more than 10 hours at work are very low. $60 \%$ of academic staff perform tasks related to academic work, $29 \%$ administrative, and $11 \%$ perform both of these. A survey suggested that $62 \%$ of workers left their previous jobs because of job-related stress (role ambiguity; role conflict). The survey also concluded that the academic staff in private universities in the UAE were more satisfied with their jobs and had a lower level of job stress (role ambiguity; role conflict). This is because of the difference in working hours, workload, appreciation, credit for good work, organization support, chance to explore oneself, increased participation in decision making, support from friends at work, and the salary (Jawabria, Alarmotia, \& Mohammed, 2019).

A study among female teachers of KSA suggested that the administration must discover ways to provide the academic staff with means of achieving a proper work-life balance, thus reducing role conflict. It was suggested that the officials in the education sector must make decisions regarding the provision of child care services and flexible working hours for working-class women with children. This will help them to balance work and family responsibilities, thereby increasing their focus at work. The negative association among role conflict, work-life balance and job satisfaction makes it a necessity to provide female teachers with an environment in which they can focus on their jobs without any problems or distractions (Almutairi, 2017).

Another study, which focused on full-time academic staff from Cyprus, suggested that there was no significant association between work-family conflict and organizational commitment. Gender does not moderate the relationship either. (Allard \& Håkansson, 2017).

An increase in workload can lead to lower energy levels and potential loss of personal resources for non-work life domains, e.g., family. The work and family conflict is significantly related to organizational stressors (role conflict and role ambiguity), presenteeism and organizational justice. The study showed a higher level of work-family conflict in Lebanon and other non-Latin countries. (Ferreira, et al., 2017).

\section{a. $\quad$ Supporting Theories}

\subsection{Conservation of Resources Theory}

Conservation of resources theory (COR) was first presented by Hobfoll in 1998. This is a stress theory which describes that people are motivated to build, retain and protect resources, and the threat of any expected/potential loss of the resources may cause stress. This theory strongly explains the causes of job related stress and it can also be used in the process of generating, retaining, or protecting the resources, in order to avoid stressors (role conflict is one of them). The considered resources include time, energy, skills, money, health, and self-esteem. COR theory highlights and studies the loss of resources while balancing between work and non-work life, which generates stressors (role ambiguity and role conflict). This is why COR theory plays an important part in this study.

\subsection{Role Theory}

Role theory states that an individual plays different roles in their daily lives and all of these roles comprise different sets of tasks and responsibilities. Some of these roles may be fundamentally incompatible owing to various reasons such as time and behavioral expectation. The incompatibility between the duties of these roles causes role conflict. Balancing between roles and duties properly can reduce the role conflict. The Demand-resources model is also used to explain the antecedents of this conflict. According to the demand-resources model, resources at work and at home determine the 
level of conflict i.e., higher work/family demands accompanying higher pressure at work, greater number of children, and longer working hours may increase the conflict, and vice versa (Young, 2015).

\section{Conclusion}

It is evident that the levels of work-life balance and role conflict vary with culture. The change in levels is influenced by gender equality, individualism/collectivism and the power distance dimension of culture [ (Behan, S. Drobnič, \& Präg, 2014); (Billing, Babakus, Krishnan, Ford, \& B. N. Srivastava, 2014); (Stock, Strecker, \& Bieling, 2016)]. In the Middle Eastern region, the traditional roles for men and women are changing as economies are shifting toward western cultures. This change in the family culture has increased the responsibilities and roles for individuals. The literature review suggests that the increase in responsibilities makes it difficult to manage work and personal lives simultaneously, thus increasing the role conflict.

The two variables of Work-Life Balance (WLB) and Role Conflict are not found in many studies about the Middle East, especially in the context of academic staff. However, the literature found and supported the idea that WLB plays a vital role in the role conflict. WLB and role conflict are negatively associated with one another, which means that an increase in one causes a decrease in the other, i.e., the higher the WLB, the lower the role conflict.

\section{b. Significance of Study}

This study has a great significance, because of several reasons. One of the reasons is the increase in the significance of research on WLB and Role Conflict. It is very important for an individual, especially a teacher (because of the importance and nature of the profession), to manage their personal and professional roles properly, in order to achieve a sense of satisfaction and happiness for the benefit of the next generation.

The study will be beneficial to the government and private university owners. They can use these findings to increase the motivation and job satisfaction among academic staff. The findings can also be used to lower the degree of job stress among teachers.

\section{c. Limitations and Directions for future studies}

One major limitation of this study is that there are few papers on this subject. Moreover, very few studies were found in the Middle Eastern context. A total of 6352 articles were found under the key words which were then screened for relativity with context and topic. This process left us with 19 articles that were the most relevant. These articles were mostly focused on healthcare or the banking sector of the Middle East. Even in the Middle East, most of the articles found were focused on KSA, Oman, Turkey, or Qatar. There are 17 countries in total in the Middle East and very few articles were found that focused on any other culture/country, and further screening left us with less than 10 articles.

Future studies must also consider unpublished sources, e.g., theses, statistics maintained by officials, and other sources. The data used in this paper are from published sources only and this may not represent the population in its entirety. The future studies must include more than one sector for a better understanding of the topic.

\section{References}

Agha, K., \& Khan, S. A. (2019). WORK LIFE BALANCE AMONG TEACHERS EMPLOYED IN HIGHER EDUCATION IN OMAN: EMERGING ISSUES \& CHALLENGES. The 7th International Research Symposium of the SGBED (pp. 321-328). SGBED.

Allard, K., \& Håkansson, K. (2017). Examining the Impact of Work-Family Conflict on Organizational commitment: Study of Higher Education Sector in Northern Cyprus. Gothenburg.

Almutairi, D. O. (2017). Work-Family Conflict, Social Support and Job Satisfaction among Saudi Female Teachers in Riyadh, Saudi Arabia. Journal of Educational Sciences, 287-298. https://doi.org/10.33948/1158-029-002-005

Anaele, E. (n.d.) (2016). BURNOUT AND WORK-LIFE BALANCE AMONG UNIVERSITY TEACHERS IN NORTH CYPRUS: A CASE STUDY.

Bayraktaroglu, S., Atay, E., Ilhan, H., \& Mustafayeva, L. (2019). Work-family conflict and life satisfaction: A comparative study of academics from British and Turkish business schools. International Journal of Employment Studies. https://doi.org/10.1016/j.sbspro.2014.01.1050

Behan, B., S. Drobnič, \& Präg, P. (2014). The work-family interface of service sector workers: A comparison of work resources and professional status across five European countries. Applied Psychology, 29-61. https://doi.org/10.31235/osf.io/645ft 
Billing, R. S., Babakus, E., Krishnan, B., Ford, D. L., \& B. N. Srivastava, A. M. (2014). Work-family conflict and organisationally valued outcomes: The moderating role of decision latitude in five national contexts. Applied Psychology: An International Review, 62-95. https://doi.org/10.1111/j.1464-0597.2012.00526.x

Blake, R., \& Mouton, J. (1964). The managerial grid: The key to leadership excellence. Houston: Gulf Publishing.

Bodla, A. A., Hussain, M., \& Chen, C. (2014). Determinants of job satisfaction in academic professionals. Sukkur Institute of Business Administration, 20-39. https://doi.org/10.30537/sijmb.v1i1.75

Bowling, N. A., Khazon, S., Alarcon, G. M., Blackmore, C. E., Bragg, C. B., Hoepf, M. R., et al. (2017). Building better measures of role ambiguity and role conflict: The validation of new role stressor. Work \& Stress, 1-23. https://doi.org/10.1080/02678373.2017.1292563

Carnevale, P. J., \& Isen, A. M. (1986). The influence of positive affect and visual access on the discovery of integrative solutions in bilateral negotiation. Organizational Behavior and Human Decision Processes, 1-13. https://doi.org/10.1016/0749-5978(86)90041-5

Chapman, D., Austin, A., Farah, S., Wilson, E., \& Ridge, N. (2013). Academic staff in the UAE: Unsettled Journey. Higher Education Policy, 131-151. https://doi.org/10.1057/hep.2013.19

Dreu, C. K., Evers, A., Beersma, B., Kluwer, E. S., \& Nauta, A. (2001). A theory-based measure of conflict management strategies in the workplace. Journal of Organizational Behavior: The International Journal of Industrial, Occupational and Organizational Psychology and Behavior, 645-668. https://doi.org/10.1002/job.107

Eisenkopf, G. (2018). The long-run effects of communication as a conflict resolution mechanism. Journal of Economic Behavior and Organization, 121-136. https://doi.org/10.1016/j.jebo.2018.08.002

Ferreira, A. I., Mach, M., Martinez, L. F., Brewster, C., Dagher, G., Perez-Nebra, A., et al. (2017). Working sick and out of sorts: a cross-cultural approach on presenteeism climate, organizational justice and work-family conflic. The International Journal of Human Resource Management. https://doi.org/10.1080/09585192.2017.1332673

Friedman, R. A., Tidd, S. T., Currall, S. C., \& Tsai, J. (2000). What goes around comes around: The impact of personal conflict style on work conflict and stress. International Journal of Conflict Management, 32-55. https://doi.org/10.1108/eb022834

Haider, M., \& Agha, K. (2019). FACTORS AFFECTING WORK LIFE BALANCE AND JOB SATISFACTION - A COMPARATIVE STUDY OF FEMALE TEACHERS IN INDIA AND UAE. The 7th International Research Symposium of the SGBED (pp. 316-320). SGBED.

Hofstede, G. (1984). Culture's consequences: International differences in work-related values. Newbury Park: CA: Sage Publications.

Iqbal, A., Ali, M. S., Abbas, F., Shah, M. A.-u., \& Anjum, S. (2020). A Study of Work-Family Conflict among Elementary School Teachers. International Journal of Innovation, Creativity and Change.

Javed, M., Khan, M. A., Yasir, M., Aamir, S., \& Ahmed, K. (2014). Effect of Role Conflict, Work Life Balance and Job Stress on Turnover Intention: Evidence from Pakistan. Journal of Basic and Applied cientific Research, 125-133.

Jawabria, A., Alarmotia, A., \& Mohammed, M. A. (2019). Job stress and satisfaction among academic staffs in public universities: An empirical study in the United Arab Emirates (UAE). Management Science Letters, 973-986. https://doi.org/10.5267/j.msl.2019.4.007

Karakas, F., \& Lee, M. D. (2004). A Qualitative Investigation into the Meaning of Family Well-Being from the Perspective of Part-Time Professionals. Equal Opportunities International, 57-77. https://doi.org/10.1108/02610150410787855

Karimi, L. (2008). A study of a multidimensional model of work-family conflict among Iranian employees. Community, Work \& Family, 283-295. https://doi.org/10.1080/13668800802133958

Maceda, C. (2016). Low salary: the Top cause of stress for workers in UAE, other Mena countries. Retrieved from Gulf

News: http://gulfnews.com/business/sectors/employment/low-salary-top-cause-of-stress-forworkers-in-uae-other-menacountries-1.1898394. 
Nishaat, B. Z. (2017). Achieving work family balance (WFB) among professional working women in Mauritius: A qualitative study. PEOPLE: International Journal of Social Sciences, 2053-5074. https://doi.org/10.20319/pijss.2017.32.20532074

Rahim, A. M., Magner, R. N., Antonioni, D., \& Rahman, S. (2001). Do justice relationships with organization-directed reactions differ across US and Bangladesh employees? International Journal of COnflict Management, 333-349. https://doi.org/10.1108/eb022862

Stock, R. M., Strecker, M. M., \& Bieling, G. I. (2016). Organizational work-family support as universal remedy? A cross-cultural comparison of China, India and the USA. The International Journal of Human Resource Management, 1192-1216. https://doi.org/10.1080/09585192.2015.1062039

Tavassoli, T., \& Sune, A. (2018). A NATIONAL STUDY ON THE ANTECEDENTS AND OUTCOMES OF WORK-LIFE BALANCE IN IRAN. PEOPLE: International Journal of Social Sciences, 1616-1636. https://doi.org/10.20319/pijss.2018.33.16161636

Young, M. (2015). Family and Work. In J. D. Wright, International Encyclopedia of the Social \& Behavioral Sciences (Second Edition) (pp. 758-765). https://doi.org/10.1016/B978-0-08-097086-8.94023-6

\section{Copyrights}

Copyright for this article is retained by the author(s), with first publication rights granted to the journal.

This is an open-access article distributed under the terms and conditions of the Creative Commons Attribution license (http://creativecommons.org/licenses/by/4.0/). 